\title{
Linkage relations of a locus for congenital total nuclear cataract
}

\author{
R. S. HUNTZINGER, L. R. WEITKAMP, AND P. D. ROCA
}

From the Department of Psychiatry and Division of Genetics, and the Division of Ophthalmology, University of Rochester Medical School, 601 Elmwood Ave., Rochester, NY, U.S.A.

SUMMARY A family with an autosomal dominant form of congenital cataract, total nuclear cataract, was examined for genetic linkage between the cataract locus and 30 marker loci. Close linkage was excluded for all of the 21 informative loci. There was no significant evidence for linkage of the cataract locus with any of the marker loci.

One form of dominantly inherited congenital cataract, zonular pulverulent cataract, has been shown to be closely linked to the Duffy blood group locus (Renwick and Lawler, 1963). In other types of cataract the locus is not closely linked to the Duffy blood group locus (Marner's cataract, studied by Renwick and Lawler, 1963; central cataract, Hammerstein and Scholz, 1974) or the results are inconclusive (Coppock's cataract, Renwick, 1970). In these latter pedigrees, the cataract locus was not found to be linked to any of the marker systems examined. Here we describe a dominantly inherited form of congenital cataract, total nuclear cataract, which was examined for its linkage relations with $\mathbf{3 0}$ marker loci.

\section{Clinical description}

The pedigree of the family is given in the Figure. The proband, 001, was first examined in 1970 at the age of 3. He presented with bilateral, dense, chalk-like, white opacities mostly confined to the nucleus of the lens. There was very little cortical involvement. The right eye was more severely affected, having only light and colour perception. The left eye had hand motion perception at 6 feet. The cataracts were removed in 1970 and 1971. When last examined in 1976, his best corrected vision was $20 / 40$ on the right and $20 / 200$ on the left, because of amblyopia. No sign of other eye disease was present.

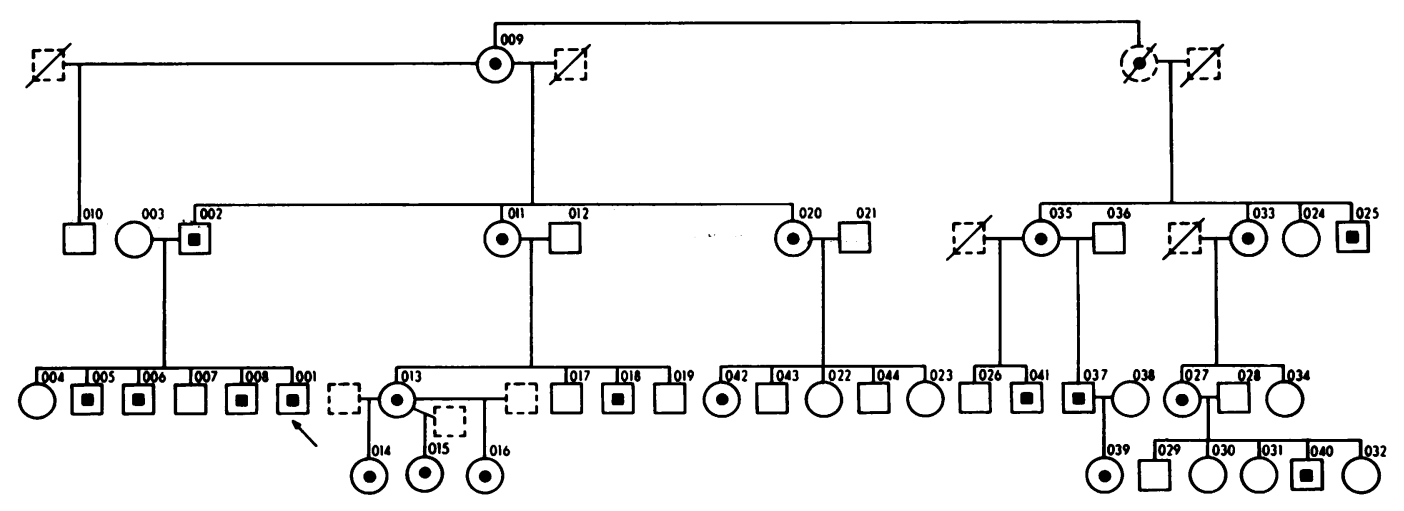

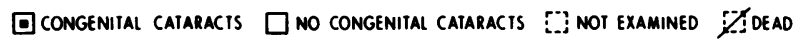

Fig. The pedigree of the family studied.

Received for publication 10 May 1977 
A brother of the proband, 005, was first examined in 1954 at 1 year of age. The ophthalmological examination was normal except for cataracts, which were similar to those described above. Both cataracts were removed in 1954. Another brother of the proband, 008, was first examined in 1968 at the age of 5. Again, he presented with cataracts similar to the proband's, but was found to have, in addition, an alternating esotropia and intermittent involuntary upward motions of the eyes, one at a time, resembling oculogyric episodes. His cataracts were removed in 1969.

The cataracts described above are, in each case, consistent with the description of total nuclear cataract given by Duke-Elder (1964).

\section{Materials and methods}

The congenital cataract in this family segregates as an autosomal dominant with complete penetrance (Fig.). Excluding the proband and his father, 54 per cent of the offspring of affected parents were also affected. Of the 22 affected subjects, 10 were male and 12 were female. Male to male transmission was observed in 4 cases, and there was no evidence of incomplete penetrance.

Forty-four members of the family were typed for 30 marker systems: ABO, Rh, MNS, Fy, Kell, Kidd, Lewis (red cells), P, Gc, Gm, Km, Lp, Ag, $\mathrm{PGM}_{1}, \mathrm{Hp}$, 6PGD, C3, AK, Tf, GPT, EsD, AcP ${ }_{1}, \mathrm{GLO}, \mathrm{Bf}$, ADA, galactose-1-phosphate uridyl transferase (Gt), transcobalamin $(\mathrm{Tc})$, serum amylase $\left(\mathrm{Amy}_{2}\right)$, and $\alpha_{1}$ antitrypsin $(\mathrm{Pi})$. Secretor types were inferred from the red cell Lewis types (see Race and Sanger, 1975). Of these systems, all except Kell, Km, Ag, 6PGD, C3, $\mathrm{AK}, \mathrm{Gt}, \mathrm{Amy}_{2}$, and Pi were informative with respect to their genetic linkage relations with the cataract locus.
The pedigree was analysed for linkage using the lod- $\Omega$ score (z score) method of Morton (1955) as implemented in the LIPED computer programme (Ott, 1976).

\section{Results and discussion}

The results of the linkage analysis are given in the $\frac{\overline{\bar{O}}}{\bar{N}}$ Table for both sexes combined, there being no $\frac{\bar{T}}{\bar{D}}$ significant evidence for an effect of sex on recom- $\stackrel{\mathbb{Q}}{\Omega}$ bination frequency, $\theta$, in the amount of data available. Very close linkage $(\theta \sim 0)$ can be excluded for all the $\vec{A}$ informative marker loci. Linkage may also be excluded $(\mathrm{z}<-2.0)$ at $\theta \leqslant 0.05$ for $\mathrm{PGM}_{1}, \mathrm{Fy}, \mathrm{AcP}_{1}, \mathrm{Bf}, \mathrm{ABO}_{\vec{w}}$ ADA, Kidd, Gc, and GPT; at $\theta \leqslant 0.10$ for EsD ando $\mathrm{Gm}$; at $\theta \leqslant 0.15$ for $\mathrm{Rh}, \mathrm{GLO}$, secretor and $\mathrm{Lp}$; and at $\theta \leqslant 0.30$ for MNS. There is no significant evi- dence favouring linkage between the cataract locus ${ }^{r}$ and any of the informative marker loci. Since the $N$ congenital cataract in this family is not closely linked $\vec{\omega}$ to the Duffy blood group, it appears to be geneticallyo as well as clinically distinguishable from the zonular? pulverulent form in the family studied by Renwick $\vec{D}$ and Lawler (1963).

We thank Ms E. Johnston, S. Hempfling, L. Francisco $\overrightarrow{r 0}$ and S. A. Guttormsen for able technical assistance. This work was supported in part by grants from the National Institutes of Health, 5-K04-HD-502480 and 1-R01-GM-19962, the National Institutes of Mental Health, 9-K02-MH00124 and 1-T32-MH-O 14650 , and National Foundation grant 1-443.

\section{References}

Duke-Elder, W. S. (1964). System of Ophthalmology, Vol. III.马 Normal and Abnormal Development. Part 2, Congenital Deformities. Henry Kimpton, London.

Hammerstein, W., and Scholz, W. (1974). Familiäre Form einer 'Cataracta centralis' Klinisch-genetische Studie mit Koppe $\overline{\overline{3}}$ lungsdaten. Albrecht von Graefes Archiv für klinische undQ experimentelle Ophthalmologie, 189, 9-19.

Table Lod scores for linkage between congenital cataract and 21 marker loci

\begin{tabular}{|c|c|c|c|c|c|c|c|}
\hline \multirow[t]{2}{*}{ Chromosome } & \multirow[t]{2}{*}{ Locus } & \multicolumn{6}{|c|}{ Recombination frequency } \\
\hline & & 0.00 & 0.05 & $0 \cdot 10$ & $0 \cdot 20$ & $0 \cdot 30$ & 0.40 \\
\hline $\begin{array}{c}2 \\
6 \\
9 \\
13 \\
16 \\
20 \\
\text { Unassigned }\end{array}$ & $\begin{array}{l}\text { Rh } \\
\text { PGM } \\
\text { Fy } \\
\text { AcP }_{1} \\
\text { GLO } \\
\text { Bf } \\
\text { ABO } \\
\text { EsD } \\
\text { Hp } \\
\text { ADA } \\
\text { MNS } \\
\text { P } \\
\text { Jk } \\
\text { Le } \\
\text { Se } \\
\text { Gc } \\
\text { Gm } \\
\text { Lp } \\
\text { Tf } \\
\text { GPT } \\
\text { Tc }\end{array}$ & $\begin{array}{l}-\infty \\
-\infty \\
-\infty \\
-\infty \\
-\infty \\
-\infty \\
-\infty \\
-\infty \\
-\infty \\
-\infty \\
-\infty \\
-\infty \\
-\infty \\
-\infty \\
-\infty \\
-\infty \\
-\infty \\
-\infty \\
-\infty \\
-\infty \\
-\infty\end{array}$ & $\begin{array}{r}-6.77 \\
-2.86 \\
-2.96 \\
-2.06 \\
-4.90 \\
-2.16 \\
-2.40 \\
-4.80 \\
-0.34 \\
-2.43 \\
-11.57 \\
-0.11 \\
-3.06 \\
-0.16 \\
-4.05 \\
-2.37 \\
-3.71 \\
-4.62 \\
-1.33 \\
-2.97 \\
-0.56\end{array}$ & $\begin{array}{r}-3.66 \\
-1.95 \\
-1.46 \\
-0.72 \\
-3.14 \\
-1.41 \\
-1.43 \\
-2.70 \\
0.15 \\
-1.58 \\
-7.80 \\
0.09 \\
-1.74 \\
0.05 \\
-2.81 \\
-1.35 \\
-2.24 \\
-3.09 \\
-0.56 \\
-1.85 \\
0.10\end{array}$ & $\begin{array}{r}-1.13 \\
-0.99 \\
-0.33 \\
0.12 \\
-1.50 \\
-0.73 \\
-0.57 \\
-0.96 \\
0.46 \\
-0.78 \\
-4.28 \\
0.20 \\
-0.62 \\
0.17 \\
-1.53 \\
-0.51 \\
-0.91 \\
-1.61 \\
0.03 \\
-0.82 \\
0.49\end{array}$ & $\begin{array}{r}-0.16 \\
-0.47 \\
0.00 \\
0.22 \\
-0.67 \\
-0.32 \\
-0.19 \\
-0.25 \\
0.46 \\
-0.37 \\
-2.38 \\
0.17 \\
-0.16 \\
0.16 \\
-0.77 \\
-0.17 \\
-0.31 \\
-0.82 \\
0.21 \\
-0.32 \\
0.48\end{array}$ & $\begin{array}{r}0.12 \\
-0.17 \\
0.02 \\
0.08 \\
-0.22 \\
-0.08 \\
-0.03 \\
0.02 \\
0.30 \\
-0.13 \\
-1.04 \\
0.10 \\
0.01 \\
0.09 \\
-0.29 \\
-0.02 \\
-0.05 \\
-0.32 \\
0.18 \\
-0.08 \\
0.29\end{array}$ \\
\hline
\end{tabular}


Morton, N. E. (1955). Sequential tests for the detection of linkage. American Journal of Human Genetics, 7, 277-318.

Ott, J. (1976). A computer program for linkage analysis of general human pedigrees. American Journal of Human Genetics, 28, 528 529.

Race, R. R., and Sanger, R. (1975). Blood Groups in Man, 6th ed. Blackwell Scientific Publications, Oxford.

Renwick, J. H. (1970). Eyes on chromosomes. Journal of Medical Genetics, 7, 239-243.

Renwick, J. H., and Lawler, S. D. (1963). Probable linkage between a congenital cataract locus and the Duffy blood group locus. Annals of Human Genetics, 27, 67-84.

Requests for reprints to $\mathrm{Dr}$ Rand S. Huntzinger, Division of Genetics, The University of Rochester School of Medicine and Dentistry and Strong Memorial Hospital, 601 Elmwood Avenue, Rochester, New York 14642, U.S.A. 